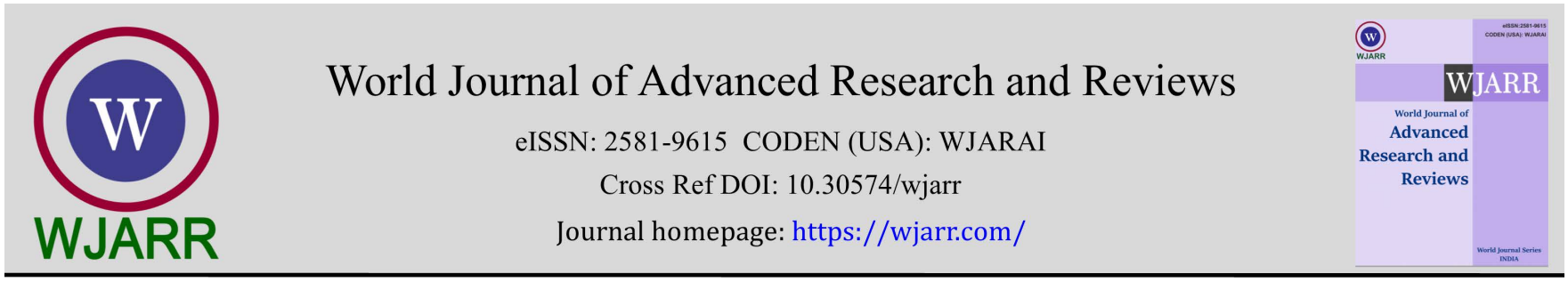

(CASE REPORT)

Check for updates

\title{
Intestinal obstruction due to phytobezoar: A rare case in a 6-year-old Sudanese girl
}

\author{
Sami Abdel-Dayem ${ }^{1}$ and Omer Saeed Magzoub Alhaj 2,* \\ ${ }^{1}$ Science \& Technology University, Khartoum, Sudan. \\ 2 Pediatrician, Ain Al-Khaleej Hospital, Abu Dhabi, UAE
}

World Journal of Advanced Research and Reviews, 2021, 12(03), 556-559

Publication history: Received on 21 November 2021; revised on 26 December 2021; accepted on 28 December 2021

Article DOI: https://doi.org/10.30574/wjarr.2021.12.3.0733

\begin{abstract}
We here report a rare case of a 6-year-old Sudanese girl diagnosed at laparotomy with phytobezoar (A phytobezoar is a type of bezoar, or trapped mass in the gastrointestinal system, that consists of components of indigestible plant material, such as fibers, skins and seeds) with good outcome.
\end{abstract}

Keywords: Phytobezoar; Intestinal obstruction; Sudanese girl: Case Report

\section{Introduction}

Bezoars can result from any indigestible or poorly digestible substances that are capable of forming concretions within gastrointestinal tract including the stomach and small intestine, when concretions of vegetable matters are composed of they are called Phytobezoars.

Most of patients with bezoars are asymptomatic but intestinal obstruction has been reported on the other hand small intestinal phytobezoars are almost always obstructive. Intestinal perforation secondary to obstruction is not well documented in the literature [1]. Clinical presentation varies but they often present with abdominal pain, anorexia or vomiting, anemia and malnutrition of different degrees [2]. Neurologically impaired children are at increased risk of gastric bezoar due to altered gastrointestinal motility and ineffective chewing. [3].

\section{Case report}

A 6-year-old Sudanese girl presented with greenish vomiting, absolute constipation, mild abdominal distension and severe abdominal pain for a few days. Abdominal examination revealed tense abdomen with mild tenderness, right iliac fossa hard mass and exaggerated bowel sounds.

Lab investigations showed high TWBC mainly neutrophils. Other routine basic investigations (CBC, CRP, RFTs and Electrolytes) were within normal limits and abdominal X-rays showed multiple air-fluid levels.

Patient underwent immediate laparotomy; there was ilio-ilial intussusception and a large and hard ilial mass about 25 $\mathrm{cm}$ proximal to ilio-cecal valve. The intussusception resolved spontaneously. Transverse enterotomy was made in distal ileum and a large and long cast of dry grass was gradually extracted from the ileum (figure 1\&2) and the enterotomy was closed in two layers. A thorough exploration of the small bowel and the stomach for a concomitant bezoar was unremarkable. She had smooth post-operative recovery and started oral intake on day 3 and discharged on day 5 . She was referred to pediatric psychiatrist after discharge for evaluation.

\footnotetext{
* Corresponding author: Omer Saeed Magzoub Alhaj

Pediatric and Child Health, Nile College, Khartoum, Sudan.
}

Copyright (C) 2021 Author(s) retain the copyright of this article. This article is published under the terms of the Creative Commons Attribution Liscense 4.0. 


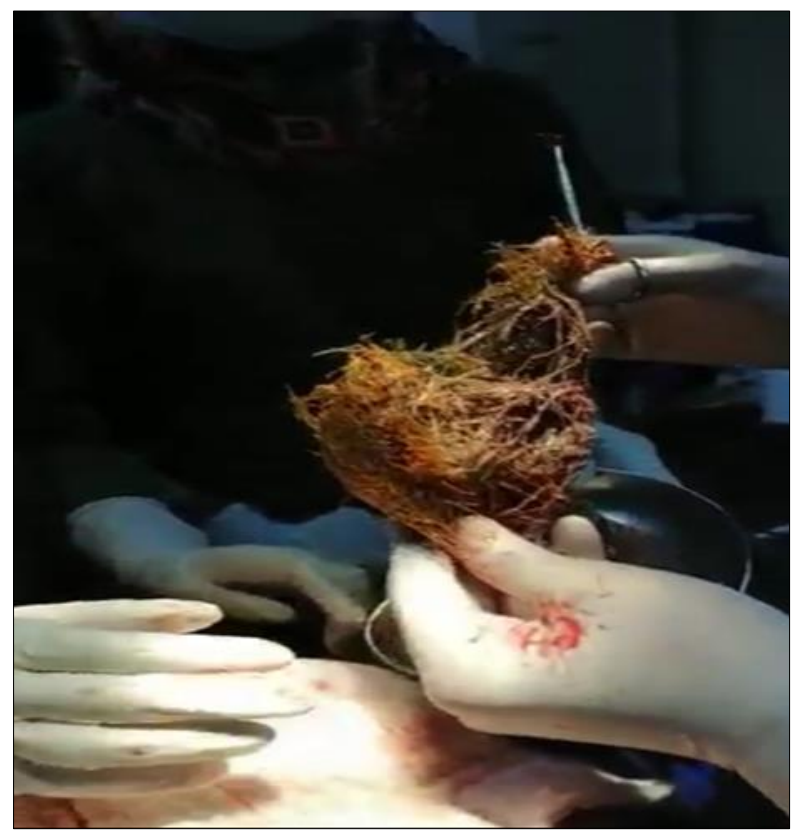

Figure 1 Dry grass extracted from the ileum

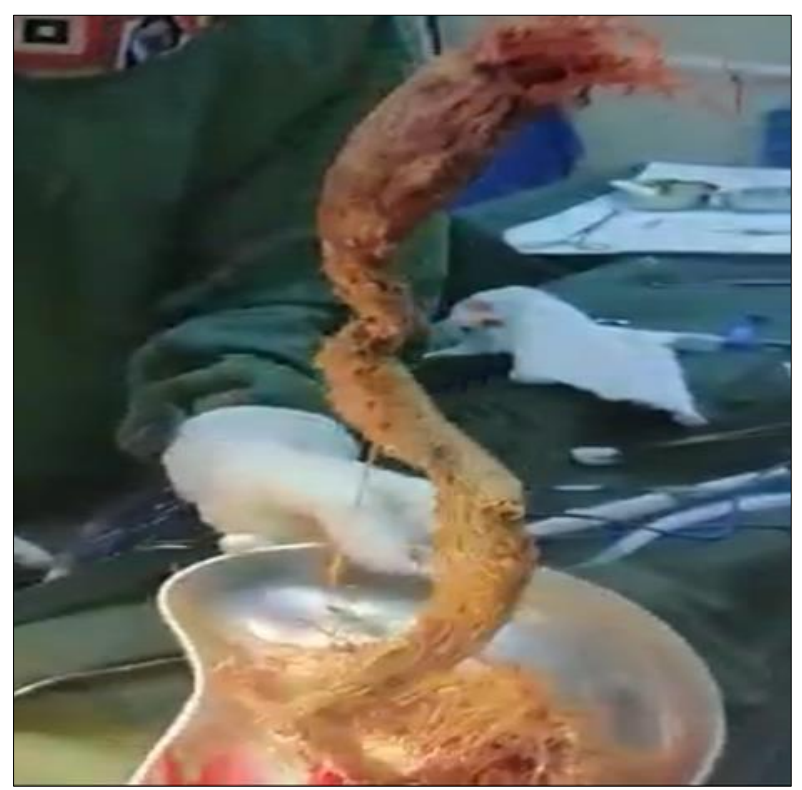

Figure 2 Dry grass extracted from the ileum

\section{Discussion}

Infants and children sometimes acquire the habit of swallowing foreign materials this may lead to formation of bezoar which is a collection of indigestible material in gastrointestinal tract.. This habit is more common in mentally disturbed children and in those with history of trichotillomania and visible hair loss may be present in these patients [4]. Other predisposing factors are ingestion of high-fiber diet, abnormal chewing, diminish gastric secretion and motility, hypothyroidism, and myotonic dystrophy [5].

Baudament in 1779 first described bezoars as a human disease and later in 1883 Schonborn carried out first surgical removal in humans. DeBakey and Ochsner concluded that in total cases of bezoars, about $18 \%$ were found in the first decade, $37 \%$ during the second and $27 \%$ in the third. Gaston reported the first case of bezoar in a one-year-old infant [4]. 
Bezoars are classified into five subgroups according to composition: (1) phytobezoars (indigestible vegetables \& fruits); (2) pharmacobezoar (composed of undigested medications) (3) trichobezoars (composed of hair); (4) lactobezoar (reported only in neonatal period \& consisted of ingested milk); (5) foreign body bezoar (chewing gum candy, toilet paper \& sunflower seeds) [6]. In paediatric age group, bezoar containing cotton threads have been rarely reported [1].

Patients with gastric bezoars often present with abdominal pain, anorexia or vomiting, anemia and malnutrition of different degrees [2]. Small bowel obstruction secondary to bezoar impaction is considerably less common, with the report frequency around $0.4-4 \%$ of all causes of intestinal obstruction in pediatric population [4]. However Primary small bowel bezoars almost always present as intestinal obstructions. They usually become impacted in the narrowest portion of the small bowel, the most common site being the terminal ileum, as was found in our patient, followed by the jejunum [8].

Radiologic investigations include abdominal radiography to reveal any distended gastric antrum, with associated dilated small bowel loop (Rapunzel Syndrome), chest radiography to reveal any air under the diaphragm signifying intestinal perforation. Ultrasound abdomen can be performed to evaluate the nature, size, and position of the mass. Computerized tomography could also be performed to better delineate the mass [9].

Oesophagogastroduodenoscopy is indicated for definitive diagnostic and therapeutic purposes in gastric bezoars. The procedure enables direct visual assessment of the mass and any ulcers. Therapeutically, it could remove the mass and treat the associated ulcers. However, oesophagogastroduodenoscopy is not always effective and at time associated with risk of intestinal perforation [9].

The treatment of choice for small bowel obstruction (SBO) due to bezoar is surgery. In most cases, the impaction of bezoar takes place in the narrowest segment of the small bowel [10]. Surgical options reported are manual fragmentation of bezoar and pushing it toward cecum. If it is not possible enterotomy should be done to remove the bezoar. Segmental bowel resection and anastomosis may be required in presence of complications such as gangrene of bowel [7]. During surgery, thorough exploration of abdominal cavity should be done to exclude the presence of concomitant gastric bezoar or intestine bezoars. About one third of patients have multiple intestinal bezoars [11].

Coca-Cola has been recognized as an effective method of treatment for several types of bezoars. The patients required 6-8 weeks of treatment before complete resolution. The currently accepted practice of treating bezoars with Coca-Cola should remain the first method of management. [12]

Complications of bezoar and its treatment include weight loss, malnutrition, anemia, gastric ulcer, bowel obstruction, and surgical complications. Gastric perforation, coagulopathy, and pneumococcal peritonitis are also reported as well as weight loss, malnutrition, ulcers, and wound dehiscence. [9].

Recurrence is common unless the underlying predisposing condition is corrected. The best way to manage bezoar is prevention by good eating habits, avoiding high fiber diet, introducing prophylactic medications to improve gastric motility and psychiatric follow up in patients with psychiatric disorders [7].

Further management is necessary to avoid further recurrences. Up to $20 \%$ can have recurrent bezoar. This can be minimized by prompt psychiatric referral and follow-up [13].

\section{Conclusion}

Bezoars are rare cause of small bowel obstruction. It requires a high index of suspicion especially in pediatrics with psychological illnesses.

\section{Compliance with ethical standards}

\section{Acknowledgments}

The authors would like to thank the patient and his family to participate in this case presentation as well as the hospital administration and staff who participated in the management of the case. 


\section{Disclosure of conflict of interest}

None.

\section{Statement of informed consent:}

Informed consent was obtained from the parent of the patient.

\section{References}

[1] Sethi P, Ujawal S. Hair-cotton threads bezoar in two years child. J Coll Physicians Surg Pak. 2014; 24(Suppl 3): 265-266.

[2] Boia ES, Popescu C, Trailescu M, Pavel A. Trichobezoar With Large Bowel Obstruction in Children-Case Report. I. RADIOLOGY. 2008; 42.

[3] Dörterler ME, Günendi T, Çakmak M, Shermatova S. Bezoar types in children and etiological factors affecting bezoar formation. 2020.

[4] Friedlander FC, Kushlick P. Trichobezoar. Archives of disease in childhood. 1954; 29(148): 556.

[5] Teng HC, Nawawi O, Ng KL, Yik YI. Phytobezoar: an unusual cause of intestinal obstruction. Biomed. Imaging Interv. J. 2005; 1: e4.

[6] Balamtekin N, Cakir M, Polat Z, Vurucu S, Bagci S. Case Report A Rare Cause of Vomiting in a Neurologically Impaired Child: Phytobezoar HK J Paediatr (new series). 2011; 16(4): 289-291.

[7] Erzurumlu K, Malazgirt Z, Bektas A, Dervisoglu A, Polat C, Senyurek G. Gastrointestinal bezoars: a retrospective analysis of 34 cases. World J. Gastroenterol. 2005; 11: 1813--1817.

[8] Lee JF, Leow CK, Lai PB, Lau WY. Food bolus intestinal obstruction in a Chinese population. Aust N Z J Surg. 1997; 67: 866-868.

[9] Castle SL, Zmora O, Papillon S, Levin D, Stein JE. Management of complicated gastric bezoars in children and adolescents. Isr Med Assoc J. 2015; 17(9): 541-544.

[10] Lo CY, Lau PW. Small bowel phytobezoars: an uncommon cause of small bowel obstruction. Aust. N. Z. J. Surg. 1994; 64: 187-189.

[11] Salemis NS, Panagiotopoulos N, Sdoukos N, Niakas E. Acute surgical abdomen due to phytobezoar-indusedileal obstruction. J. Emerg. Med. 2013; 44(1): e21-e23.

[12] Naramore S, Virojanapa A, Bell M, Jhaveri PN. Bezoar in a pediatric oncology patient treated with coca-cola. Case reports in gastroenterology. 2015; 9(2): 227-232.

[13] Nain Rattan, et al, childhood bezoars, Journal of Clinical and Diagnostic Research. 2018; 12(7). 